\title{
Deformation behavior of steel-to-aluminum tailor blanks made by laser/MIG hybrid and cold metal transfer brazing methods
}

\author{
M. A. Shaker ${ }^{1} \cdot$ M. K. Jain ${ }^{1} \cdot$ J. Z. Chen ${ }^{2}$ \\ Received: 24 April 2020 / Accepted: 25 August 2020 / Published online: 19 September 2020 \\ (C) The Author(s) 2020
}

\begin{abstract}
In this paper, dual phase steel (DP780) and AA2024-T3 aluminum sheets were successfully butt-welded together utilizing laser/MIG hybrid and cold metal transfer (CMT) brazing methods. A comparative study was conducted between the brazed joints produced by both methods in terms of wetting length, intermetallic compounds (IMCs) layer thickness, fracture position, and fracture mode. The results of testing showed that the produced joints from each method introduced significantly different deformation behavior. In addition, better wetting length and lower IMCs layer thickness are not the only factors that improve the mechanical behavior of brazed joints. The susceptibility of the aluminum base metal and time of exposure to the heat sources during joining process are also important.
\end{abstract}

Keywords Steel/aluminum joints $\cdot$ Laser/MIG $\cdot$ Hybrid brazing $\cdot$ CMT brazing $\cdot$ Miniature tensile test

\section{Introduction}

With greater emphasis on environmental regulations and fuel efficiency, lightweight metal alloys such as aluminum alloys are being increasingly utilized in fabricating automotive, aerospace, and other body structures and skin panels. Low density, high specific strength, good workability, superior corrosion resistance, dimensional stability, and recyclability make these lightweight metal alloys the preferred choice for many applications [17]. Therefore, many conventional all-steel body structures nowadays are being considered for replacement with hybrid steel and aluminum parts, thus requiring the development of technologies for joining of aluminum to steel [24]. Tailored blanks (TBs) made from joining steel and aluminum sheets for subsequent shaping

M. A. Shaker

moh.shaker@mtc.edu.eg

M. K. Jain

jainmk@mcmaster.ca

J. Z. Chen

jameszheng@canada.ca

1 Department of Mechanical Engineering, McMaster University, 1280 Main St. West, Hamilton, ON, L8S 4L7, Canada

2 CanmetMATERIALS, Natural Resources Canada, 183 Longwood Rd S, Hamilton, ON, L8P 0A5, Canada are of much interest to the manufacturing industry. Such a combination, if properly joined, can provide benefit from higher structural rigidity of steels and the lightweight of aluminum. In the last two decades or so, steel/aluminum TBs are being increasingly used or considered for current and future applications such as automotive and aerospace constructions as they offer attractive combination of strength and performance in applications where weight reduction is desirable. For example, by 2025 in North America, 16\% of all the body structure and closure parts, on a volume basis, for light vehicles will be made of aluminum sheets. This means, aluminum sheets for light vehicle bodies and closure parts will grow from less than 1 billion pounds in 2015 to nearly 4 billion pounds by 2025 [3].

Brazing is especially attractive for creating tailored steel/aluminum blanks. However, there are many insurmountable challenges in welding the two materials together due to their incompatible thermo-physical properties. Since, the melting temperatures of aluminum and steel are quite different, most conventional fusion welding processes do not yield a sound joint [16]. Moreover, the near-zero solubility between aluminum and steel, poor wetting behavior of aluminum, and other differences in physical and chemical properties of the base metals result in the formation of brittle intermetallic compounds (IMCs) layer in the steel/aluminum faying surfaces [7, 21]. These IMCs form barriers to the welding process of steel to aluminum and lead to a fast fracture of the joint under dynamic (and even static) 
Table 1 Brazing parameters for steel-to-aluminum joints

\begin{tabular}{|c|c|c|}
\hline & Laser/MIG & CMT \\
\hline & \multicolumn{2}{|c|}{$\begin{array}{l}\text { AA2024-T3/DP780 } \\
(1.27 \mathrm{~mm} / 1 \mathrm{~mm})\end{array}$} \\
\hline Power $(\mathrm{kW})$ & 2.3 & - \\
\hline Welding speed (m/min) & 5.75 & 0.3 \\
\hline Spot size $(\mathrm{mm})$ & 0.6 & - \\
\hline Focal length (mm) & 300 & - \\
\hline Defocus distance (mm) & -6 & - \\
\hline Working angle $\left(^{\circ}\right)$ & 6 & 0 \\
\hline Filler material & $\mathrm{AlSi}_{3} \mathrm{Mn}_{1}$ & $\mathrm{AlSi}_{3} \mathrm{Mn}_{1}$ \\
\hline Feed rate $(\mathrm{m} / \mathrm{min})$ & $\backsim 10$ & $\backsim 3.5$ \\
\hline Shielding gas (L/min) & $\operatorname{Argon}(20)$ & $\operatorname{Argon}(20)$ \\
\hline current (A) & - & 32 \\
\hline Voltage (V) & - & 20 \\
\hline Frequency $(\mathrm{Hz})$ & - & 22 \\
\hline
\end{tabular}

stress and consequently affect post-joining deformation and forming [13].

Many studies have shown that the $\left(\mathrm{Fe}_{x}-\mathrm{Al}_{y}\right)$ IMCs layer thickness is a major concern in steel-to-aluminum dissimilar brazed joints. Kreimeyer and Sepold [9] proposed that IMCs layer thickness of less than $10 \mu \mathrm{m}$ could result in a more mechanically sound joint. Ozaki and Kutsuna [14] proposed that if the thickness of brittle IMCs layer is minimized and the formation of more ductile IMCs is promoted, more reliable joints could be obtained. Shi et al. [20], in their study of the relation between IMCs layer thickness and welding time, showed that IMCs layer thickness in the interface increased with the increase in welding time and the strength of the joint was inversely related to the IMCs layer thickness. Therefore, a thinner IMCs layer contributes to improved steel-to-aluminum dissimilar joint strength.

Most researchers believe that an efficient means to reduce phase formation, and potential reduction in joint brittleness, is by limiting the time when the joining zone is at elevated temperature [13]. Some studies utilized nonfusion joining processes in order to minimize the heat input during joining and consequently overcoming the problem of brittle IMCs formation. Processes such as resistance welding [26], friction welding [5], explosion welding [23], and ultrasonic welding [6] have been used. But these processes are only suitable for certain joint configurations, and offer lower productivity and flexibility, thus limiting their industrialscale sheet joining applications.

Ozaki et al. [15] proposed that controlling heat input with a suitable time-temperature cycle during fusion welding process, it may be possible to attain optimized steel/aluminum joints. Based on this concept, laser welding provides advantages over conventional fusion joining methods in terms of weld quality, high welding speed, flexibility, localization of fusion with reduced HAZ, and accurate control of heat input during welding [11]. In particular, hybrid welding processes such as laser/MIG hybrid brazing, where two distinct welding methods are used simultaneously to take advantage of both methods, have shown to enhance plastic flow, improve elongation, shorten welding time that limits the IMCs layer thickness to a few microns, and yield better steel/aluminum brazed joints [19, 22]. Most recently, cold metal transfer (or CMT) technique, a variant of MIG welding process, was introduced by Fronius International $\mathrm{GmbH}$, Austria, in year 2005, as a means to join aluminum to galvanized steel [1]. In this method, droplet detachment occurs based on shortcircuit welding, i.e., wetting of steel substrate by melted
Fig. 1 Schematic drawing of sub-size tensile specimen

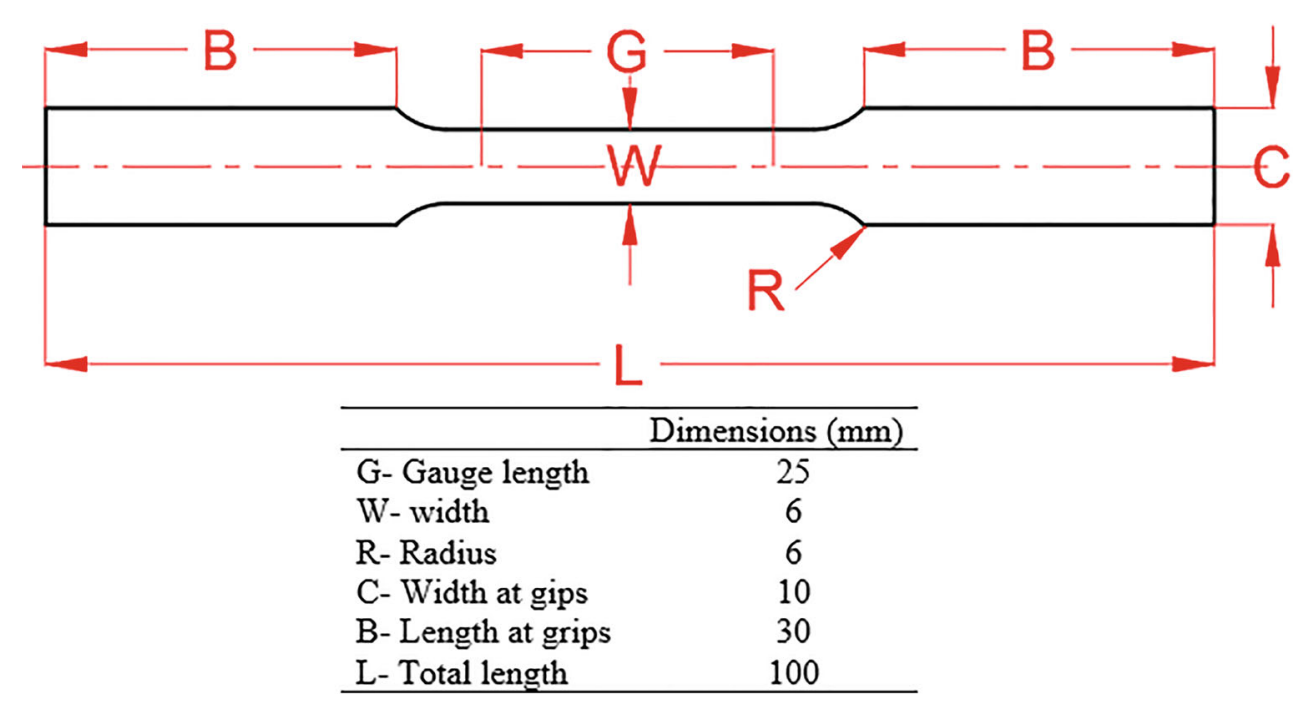


Fig. 2 Experimental setup for miniature tensile test

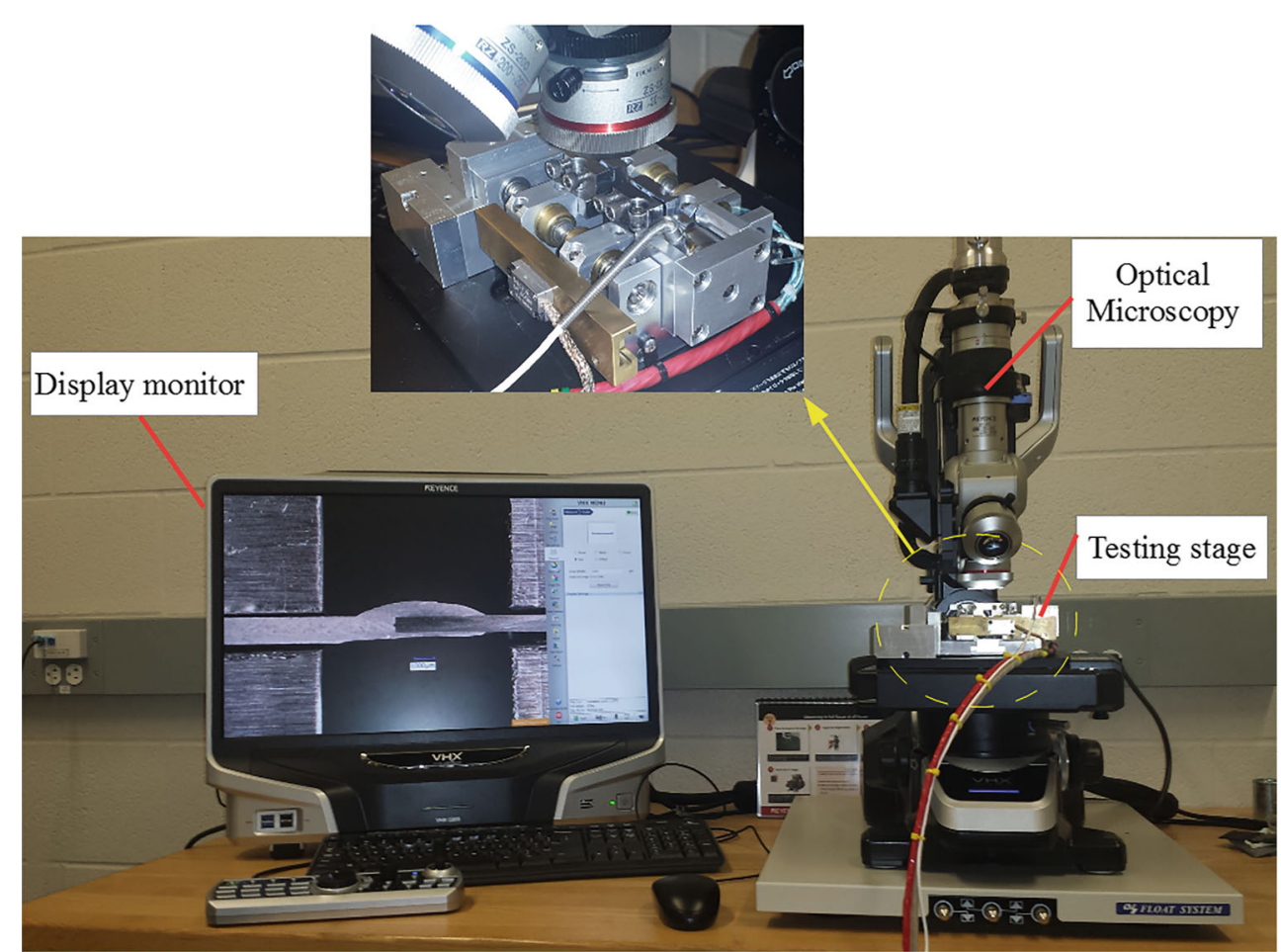

droplets of filler wire takes place in the off-current period (i.e., lower heat input period). As a result, the heat input can be minimized, thus reducing the thickness of IMCs layer, and thereby improving the mechanical properties of the brazed joints [4].

Some researchers have attempted to obtain a correlation between bonding parameters and the mechanical properties of steel/aluminum brazed joints. Möller and Thomy [13] proposed that both wetting length and the formation of IMCs in the interfacial surfaces between the braze and substrate metals have an influence on static strength. Moreover, if seam quality is sufficient, the location of fracture depends not only on wetting length but also on the cross-section of the steel/aluminum interface zone.

Despite the fact that butt joints are a common configuration that have significant application in sheet metal forming processes, most researchers studying joining of steel and aluminum prefer a lap joint configuration. It is largely because joining of steel/aluminum in butt joint configuration is relatively difficult [19]. Hence, useful studies related to the mechanical properties and the effect of sample geometries on failure location of steel/aluminum brazed joints with butt joint configuration are lacking. In this paper, butt joint configurations of dual phase steel (DP780) and
Fig. 3 Miniature in situ uniaxial tensile test jig setup,

through-thickness arrangement (right), and width region arrangement (left)
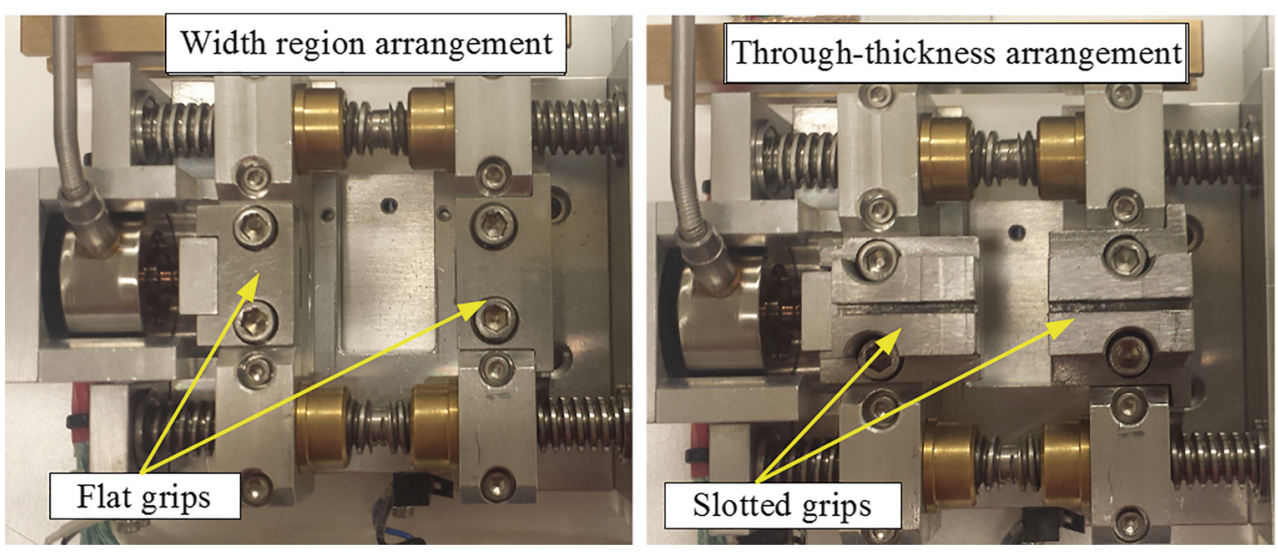


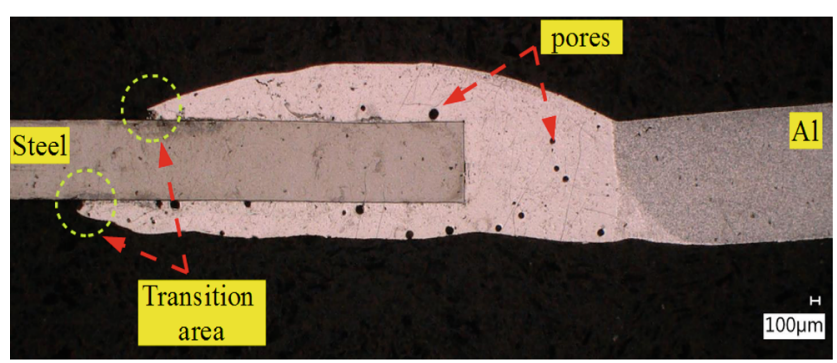

(a) Laser/MIG brazed joint cross-section .

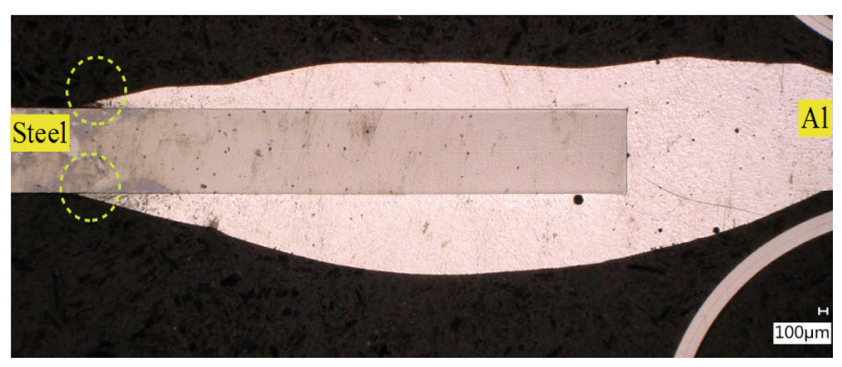

(b) CMT brazed joint cross-section.

Fig. 4 Macrograph of brazed joint cross-section of AA2024/DP780 $1.27 \mathrm{~mm} / 1 \mathrm{~mm}$ samples for a laser/MIG hybrid and b CMT brazing methods

AA2024-T3 sheets made by laser/MIG hybrid and CMT brazing methods are investigated. A comparative study is conducted between the brazed joints produced by both processes in terms of wetting length, intermetallic compounds thickness, fracture position, and fracture mode. In addition, it involves understanding of plastic deformation (general ductility), load transfer across brazed interface, and local deformation and damage initiation in the brazed interface region of steel-to-aluminum brazed joints produced by both laser/MIG hybrid and CMT brazing methods.

\section{Experimental procedures}

\subsection{Materials and samples preparations}

The materials used in the current study include galvanized dual phase (DP780) steel and aluminum alloy AA2024T3 sheets of $1 \mathrm{~mm}$ and $1.27 \mathrm{~mm}$ thicknesses respectively. For filler wire, aluminum AA4047 $\left(\mathrm{AlSi}_{3} \mathrm{Mn}_{1}\right)$ wire with diameter of $1.2 \mathrm{~mm}$ was used.

All sheets to be joined were cut to $200 \mathrm{~mm} \times 100$ $\mathrm{mm}$ pieces to create a brazed butt joint configuration of size $200 \mathrm{~mm} \times 200 \mathrm{~mm}$. The joined edges were precisely cut and milled. The sheets were cleaned with acetone to remove contaminations from the surfaces prior to brazing. For aluminum sheets, the oxide layer on the surfaces in the vicinity of the edges to be brazed was removed and gently cleaned by wire brushing with stainless steel brushes.

It is to be noted that high-strength AA2024-T3 sheets were selected to be used in the steel-to-aluminum joints because the aim of our research was to study deformation behavior at the brazed interface. Therefore, a high-strength aluminum base metal was required to be stronger than the brazed area (weld seam), to force the failure to start at the brazed region. Also, all aluminum alloys (heat-treatable and non-heat-treatable) are affected by heat during welding or brazing processes [18]. So, we need to keep the strength of aluminum base metal as high as possible after brazing process even if it is affected by the heat during brazing.

\subsection{Brazing processes}

Aluminum and steel sheets were arranged in butt joint configuration with the braze line transverse to the rolling direction, and a gap of $0.3 \mathrm{~mm}$ was maintained using a clamping fixture. For hybrid brazing, the MIG head was attached to the laser head at an angle of $35^{\circ}$ to the vertical axis of laser head. During brazing, the laser beam was positioned on the aluminum side at distance of $0.5 \mathrm{~mm}$ from

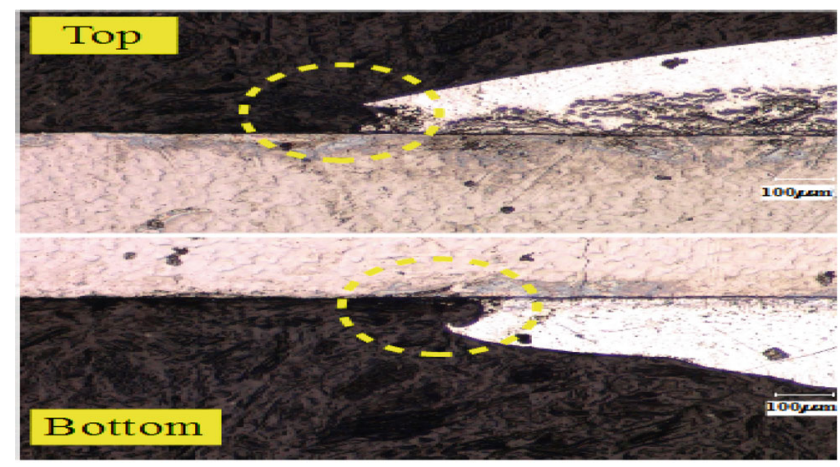

(a) Laser/MIG brazed joint.

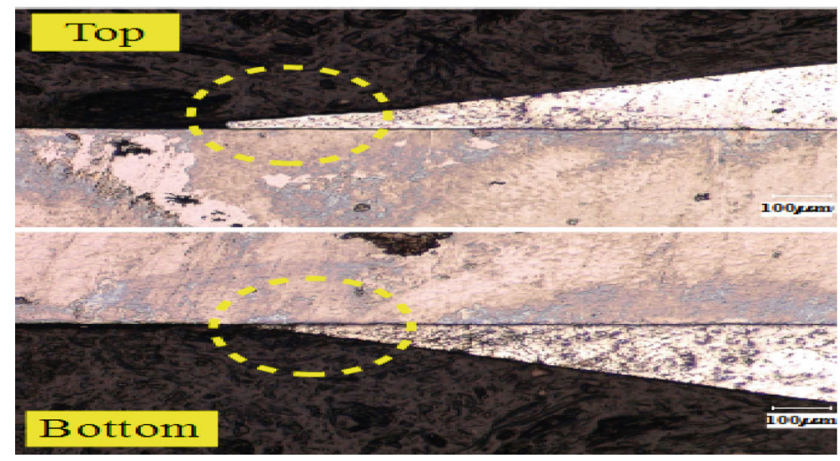

(b) CMT brazed joint.

Fig. 5 Magnified macrograph of the top and bottom transition region between brazing area and steel substrate in brazed joint for laser/MIG brazing (left) and CMT brazing (right) 


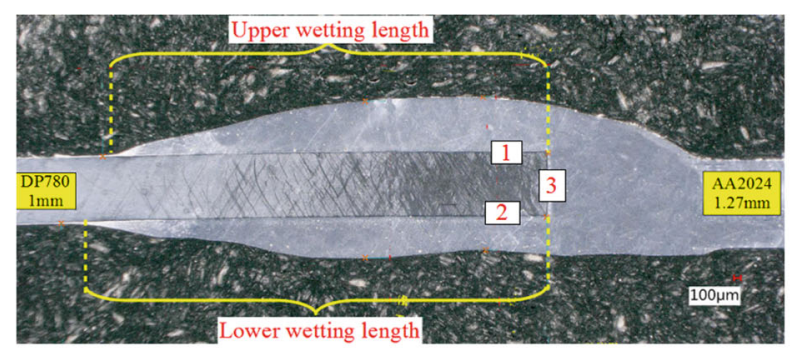

(a) AA2024/DP780 $1.27 \mathrm{~mm} / 1 \mathrm{~mm}$ brazed joint.

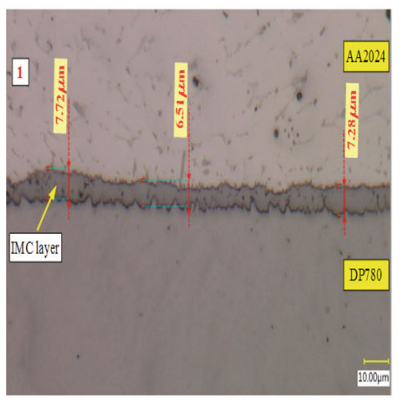

(b) Upper(laser/MIG)

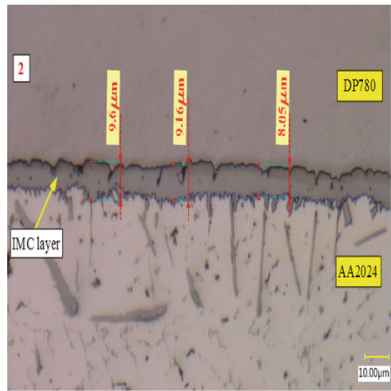

(d) Lower (Laser/MIG)

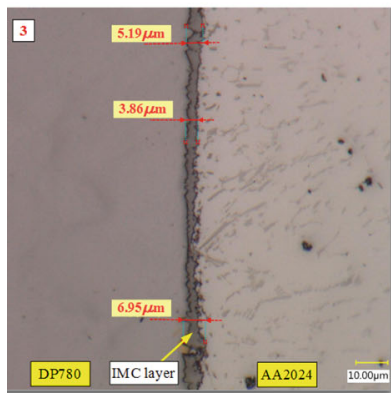

(f) Side (Laser/MIG)

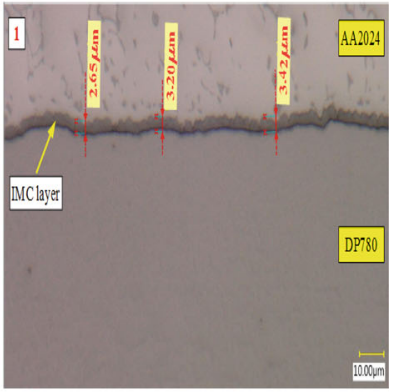

(c) Upper (CMT)

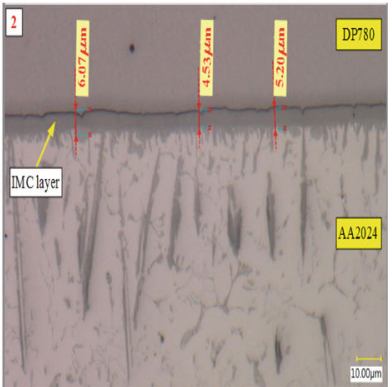

(e) Lower (CMT)

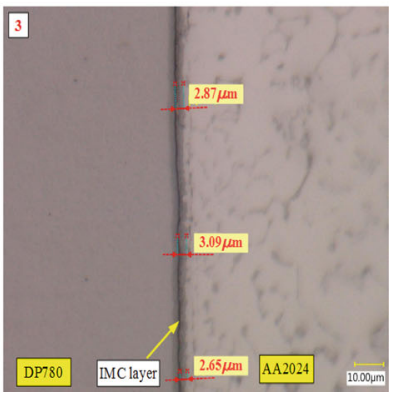

(g) Side (CMT)
Fig. 6 Micrograph of upper, lower, and side faying surfaces with IMCs layer for laser/MIG brazing method (b, d, and f) and CMT brazing method (c, e, and $\mathbf{g})$, respectively

the edge to melt the aluminum edge, whereas the projection of the $\mathrm{AlSi}_{3} \mathrm{Mn}_{1}$ filler wire of diameter $1.2 \mathrm{~mm}$ was kept behind the laser spot by approximately $5 \mathrm{~mm}$. Shielding gas (100\% argon) was fed through the MIG torch at a flow-rate of $20 \mathrm{l} / \mathrm{min}$. The laser head with MIG unit moved together along the aluminum edges of the samples to be brazed.
Table 2 Comparison between the average thicknesses of IMCs layer and the average wetting lengths for laser/MIG and CMT brazed specimens

\begin{tabular}{|c|c|c|c|c|c|}
\hline & \multicolumn{3}{|c|}{ Thickness of IMCs $(\mu \mathrm{m})$} & \multicolumn{2}{|c|}{ Wetting length (mm) } \\
\hline & Upper & Lower & Side & Upper & Lower \\
\hline Laser/MIG & 7 & 8 & 5 & 4 & 4.5 \\
\hline CMT & 3 & 5 & 3 & 6 & 6 \\
\hline
\end{tabular}

For CMT brazing process, the $\mathrm{AlSi}_{3} \mathrm{Mn}_{1}$ filler wire (electrode) of diameter $1.2 \mathrm{~mm}$ was used. The electrode was biased half of the wire diameter $(0.6 \mathrm{~mm})$ towards the aluminum sheet with zero working angle between the torch head and the normal to workpiece surface. During brazing cycle, arcing occurred by supplying a high pulse of current between filler wire (electrode) and the substrate, which caused melting of the wire tip. Then, the wire dipped into the weld pool bringing a short-circuit formation. Thereafter, the current was reduced and the arcing was extinguished. During the short-circuit, the wire was then retracted to the torch leading to the detachment of the molten droplet. The detached molten wire droplets dipped into molten aluminum and bridged the gap between the aluminum and steel and hence, steel was wetted by the molten filler wire and cold metal transfer occurred at lower current (i.e., minimum heat input). The filler wire then moved forward again and the cycle was repeated. Shielding gas (100\% argon) was fed through the torch head at a flow rate of $201 / \mathrm{min}$. The CMT cycles were repeated while the torch head moved along the aluminum edges of the sample to be brazed. The parameters for laser/MIG and CMT brazing processes are listed in Table 1.

\subsection{Material characterization}

\subsubsection{Microstructure examination}

The brazed profile cross-sections of steel-to-aluminum brazed specimens were prepared using grinding and polishing procedures to check the quality of brazed profiles, i.e., to observe if the brazed region was free from cracks and exhibited enough wetting of steel substrate. The average wetting lengths and IMCs layer thickness were measured at the faying surfaces. The brazed profiles were observed using a Keyence VHX-5000 digital optical microscope with a magnification up to $2000 \mathrm{X}$.

\subsubsection{Microhardness tests}

Vickers microhardness (HV) profiles were obtained across the braze line from through-thickness optical metallography mounts in the etched condition to reveal the microstructure. 
Fig. 7 Hardness profile along through-thickness surface of AA2024/DP780 $1.27 \mathrm{~mm} / 1 \mathrm{~mm}$ brazed specimens made by laser/MIG hybrid brazing

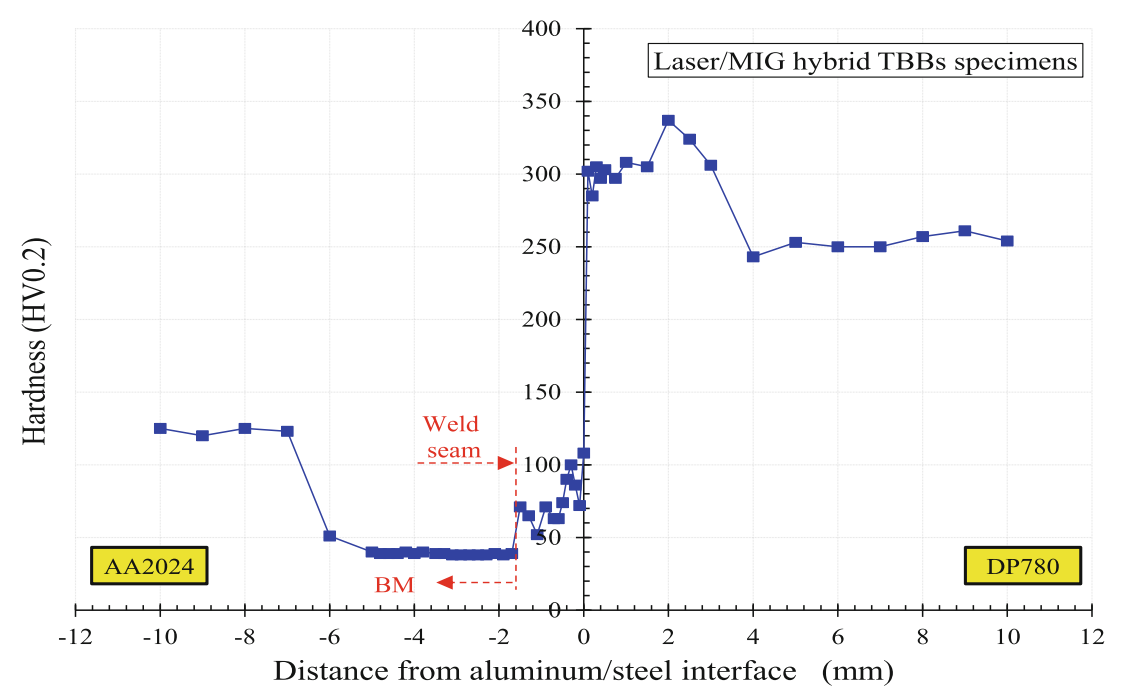

LECO M-400-H2 microhardness tester was utilized with applied load of $200 \mathrm{~g}$ and a dwell time of about $10 \mathrm{~s}$. The indentation step spacing was $0.1 \mathrm{~mm}$ to avoid interference from the strain fields between adjacent indents.

\subsubsection{Uniaxial tensile test}

Three sub-size tensile specimens from each brazing method with sufficient wetting length for both upper and bottom faying surfaces were selected and machined according to ASTM E8/E8M-13a standard [2] with geometry shown in Fig. 1 and the braze line transverse to tensile axis. The specimens were taken to fracture and assessed for fracture location, mechanical properties, and strain distribution in the vicinity of fracture. All tests were conducted using
MTS servo-hydraulic test system with $100 \mathrm{kN}$ load cell under a uniform cross-head speed of $1 \mathrm{~mm} / \mathrm{min}$. During the tensile tests, the force-displacement traces were continuously recorded during the test. Simultaneously, images were recorded from gauge region. Calculations from the recorded images were then carried out using digital image correlation (DIC) technique, Aramis ${ }^{\circledR}$ system to obtain strain maps.

\subsubsection{Miniature in situ tensile tests}

To understand how the damage initiates in the brazed specimen at the smaller-scale, a miniature in situ tensile testing jig was designed and manufactured to be used in conjunction with a high magnification digital optical
Fig. 8 Hardness profile along through-thickness surface of AA2024/DP780 $1.27 \mathrm{~mm} / 1 \mathrm{~mm}$ brazed specimens made by CMT brazing

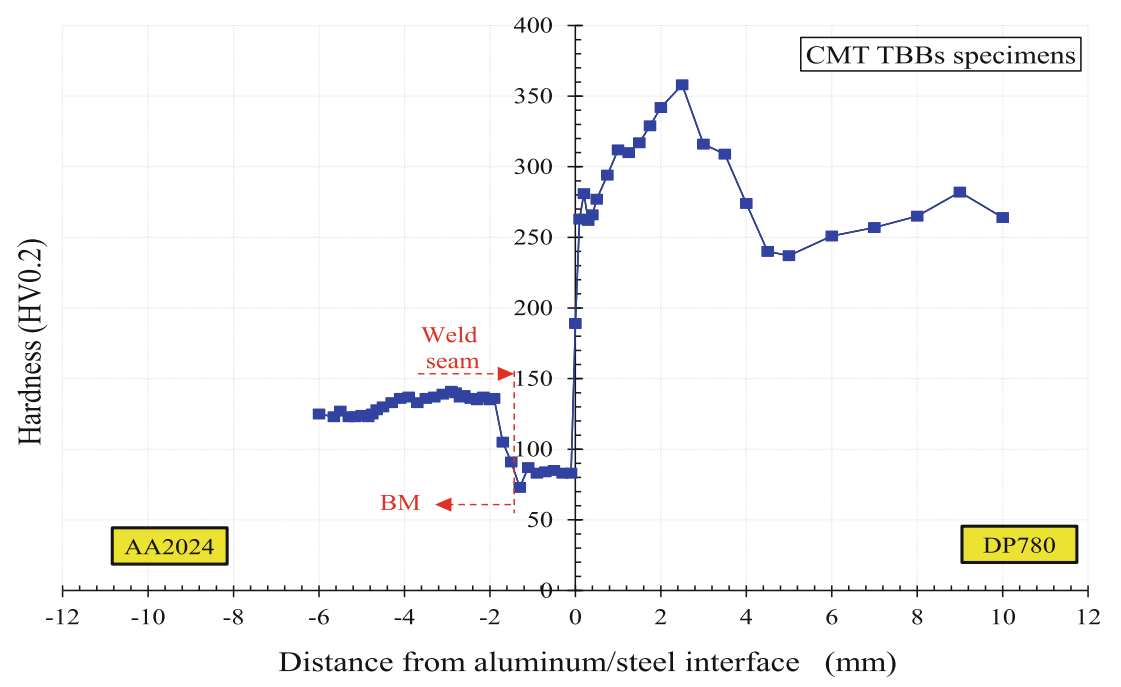


Fig. 9 Major strain mapping superimposed on the actual deformed brazed specimens of AA2024/DP780 $1.27 \mathrm{~mm} / 1 \mathrm{~mm}$ made by a laser/MIG hybrid and b CMT brazing methods

(vertical arrows indicate the direction of loading)

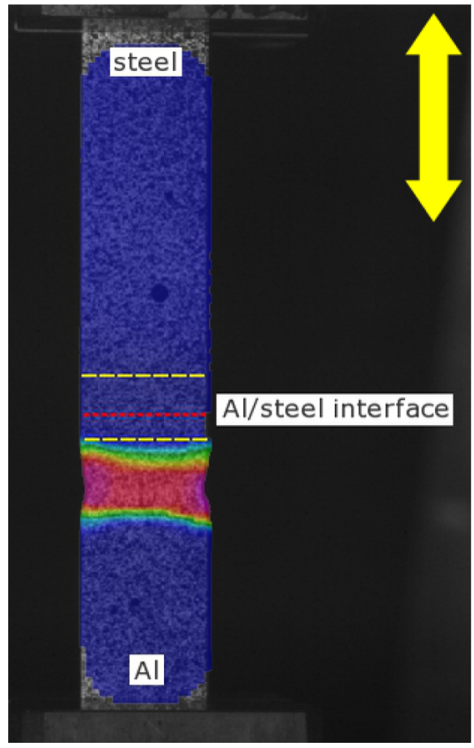

(a) Laser/MIG.

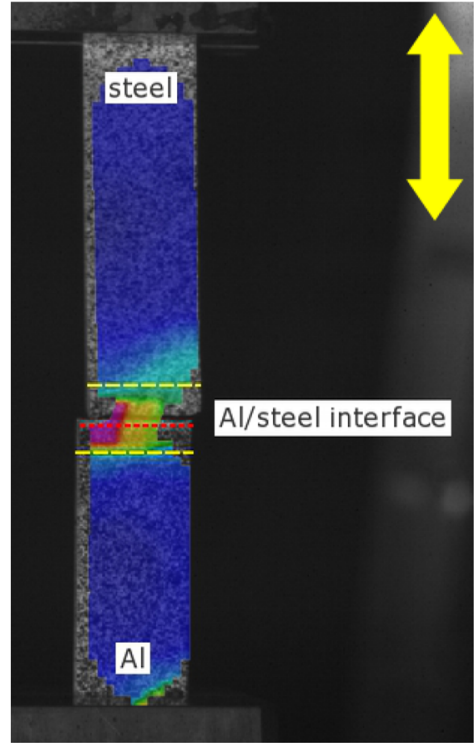

(b) CMT. microscope, as shown in Fig. 2, to simultaneously observe the plastic deformation and damage/delamination development in the critical brazed interface region.

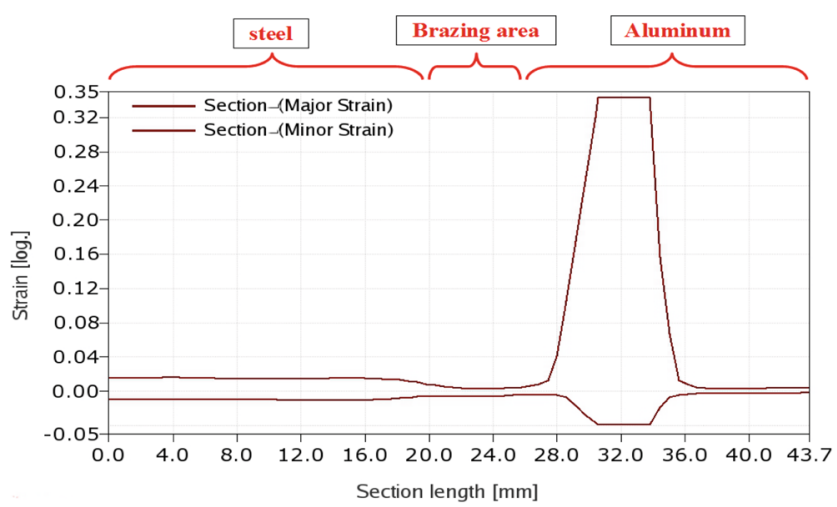

(a) Laser/MIG brazing.

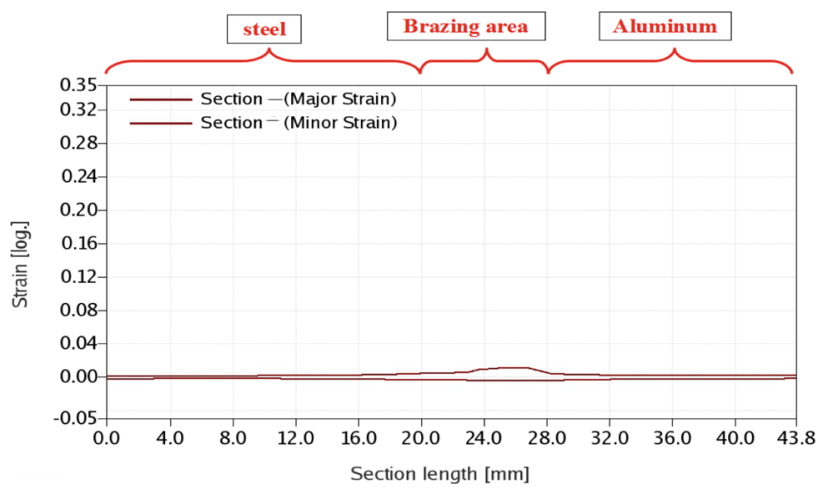

(b) CMT brazing.

Fig. 10 Major and minor strain distribution just before fracture of brazed specimens of $\mathbf{a}$ laser/MIG and $\mathbf{b}$ CMT brazing methods
Miniature brazed strips, made from both brazing methods, were precisely cut to small width $(4.5 \pm 0.1 \mathrm{~mm})$ to fit in the miniature jig grooves. Two different observation planes, long transverse (LT) and normal plane (ND), were utilized to record magnified microscope images during the test. The clamping fixtures that were specially designed for this purpose are shown in Fig. 3. For specimens observed from through-thickness (LT) plane, the specimen edges were manually polished with a series of $\mathrm{SiC}$ papers. The polished surfaces were imprinted with a very fine-scale speckle pattern. For the specimens observed from normal plane (ND), surfaces were only imprinted with a very finescale speckle pattern without any polishing. All specimens were then tested up to failure in uniaxial tension at a pulling speed of $1 \mathrm{~mm} / \mathrm{min}$ using a dedicated test controller. A series of digital images representing the deformation history of the samples were recorded by the optical microscope at a magnification of 20X. The images were then imported in the Aramis software for strain mapping measurements. The very fine speckles on the surface were then used for analyzing the local plastic deformation field and its development in the vicinity of the brazed region. The force-displacement histories of the tested specimens were also recorded using a dedicated test controller and data acquisition system.

\section{Results and discussion}

\subsection{Microstructure examination}

Figure 4 shows the profile of the brazed region of AA2024/DP780 $1.27 \mathrm{~mm} / 1 \mathrm{~mm}$ brazed joints made by 
Fig. 11 Comparison between localized true stress-true strain curves for AA2024/DP780 1.27 $\mathrm{mm} / 1 \mathrm{~mm}$ brazed specimens produced by laser/MIG and CMT brazing methods (the procedures of construction of the localized true stress-true strain curves are presented in the Appendix)

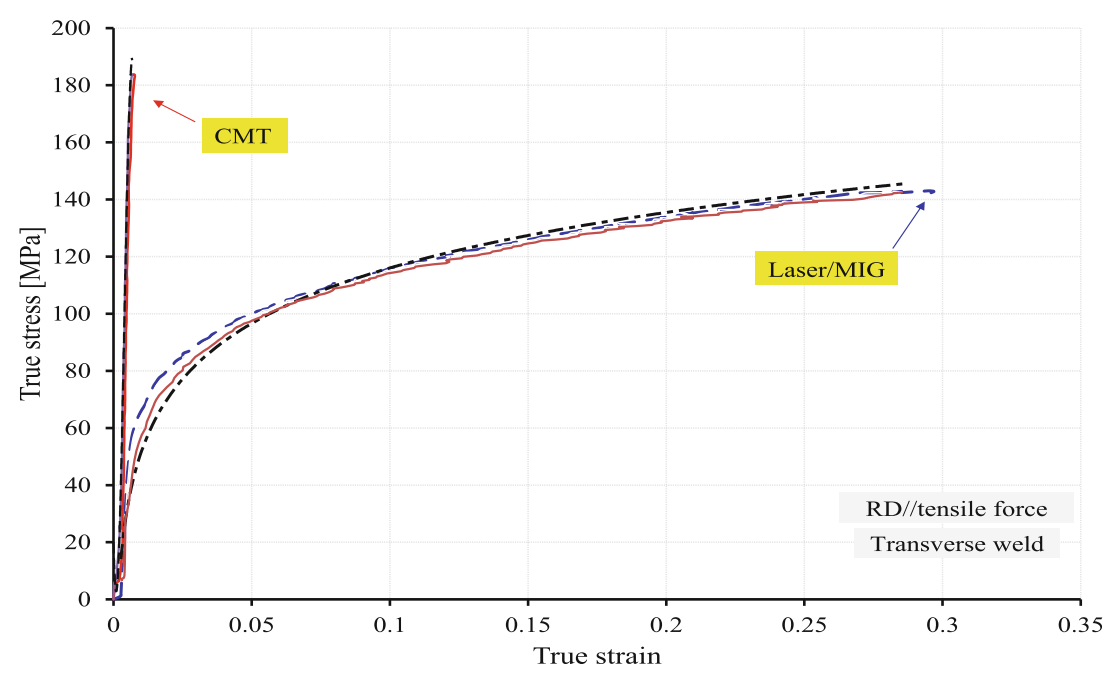

laser/MIG hybrid and CMT brazing methods. It can be seen that no cracks are observed and only aluminum sheet and filler wire were melted and wetted the steel substrate.

The microstructures revealed good adhesion at the faying surfaces for both brazing methods. However, better transition was observed between the brazing area and the steel substrate at the end of wetting lengths for CMT brazing specimens compared with laser/MIG brazing specimens (as shown by the dashed circles in Fig. 5). In addition, more pores were observed in the brazing area (weld seam) of laser/MIG brazing specimens than CMT brazing specimens. This may be attributed to the higher evaporation rate of lower melting point elements and zinc coating layer during brazing process. It is to be noted that for the laser/MIG method, wetting of steel substrate with molten aluminum occurred during fusion from both laser beam and MIG arcing (i.e., continuous heat input). In contrast, wetting in CMT brazing cycles occurred at the moment of shortcircuit or off arcing (i.e., minimum heat input) (see earlier Section 2.2).

The microstructures allowed measurement of the average upper and lower wetting lengths as well as the average thicknesses of the IMCs layer. The average upper and lower wetting lengths were almost the same for the CMT brazed specimens and longer compared with that of hybrid brazing specimens. With respect to the average thickness of the IMC layer, both methods yielded quite uniform layer thickness with values lower than the critical value of $10 \mu \mathrm{m}$ reported in the literature below which good tensile properties could be achieved [9, 13]. For laser/MIG brazed specimens, the average thickness of the IMC layer at the upper, lower, and side faying surfaces (Fig. 6b, d, and f), respectively, was higher than the corresponding IMC layer thicknesses of specimens made by CMT brazing method (Fig. 6c, e, and $\mathrm{g}$ ). It was reported that the formation of IMCs layer and its thickness is mostly related to the amount of heat

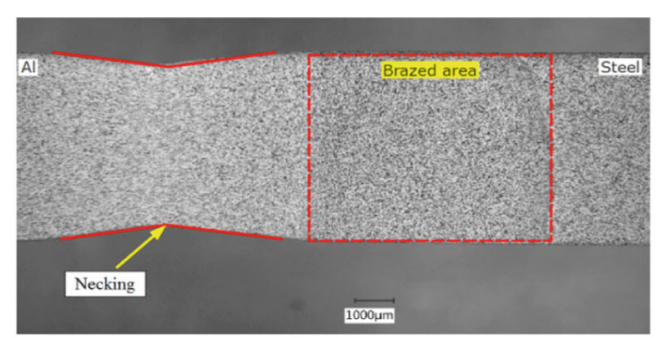

(a) Laser/MIG brazing, width region.

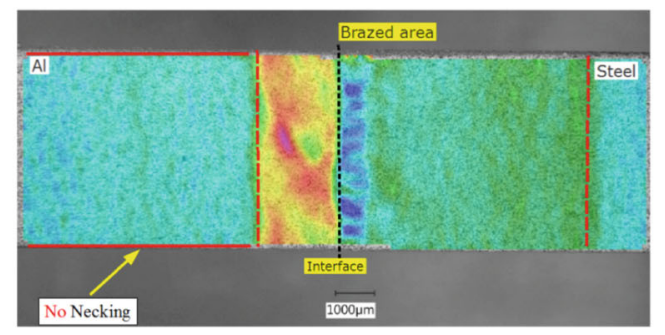

(b) CMT brazing, width region.
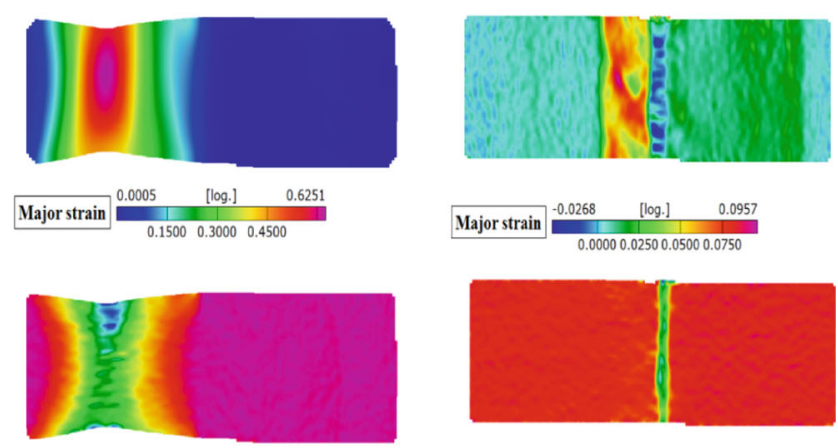

$\begin{array}{lll}\text { Minor strain } & -0.25331 \quad[\log ] \quad & 0.00453 \\ -0.15000 & -0.07500\end{array}$

(c)
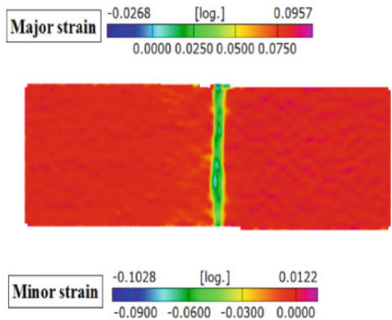

(d)

Fig. 12 Photograph of deformed samples and major and minor strain maps from width region of miniature test brazed specimens of AA2024/DP780 $1.27 \mathrm{~mm} / 1 \mathrm{~mm}$ for laser/MIG (a, c) and CMT (b, d) brazing methods 

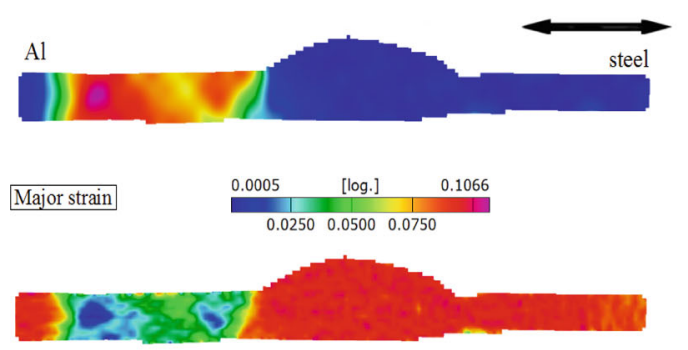

\begin{tabular}{lclll} 
& -0.08105 & {$[$ log.] } & 0.00922 \\
\hline Minor strain & -0.06000 & -0.03000 &
\end{tabular}

(a) Axial strain $=4 \%$.
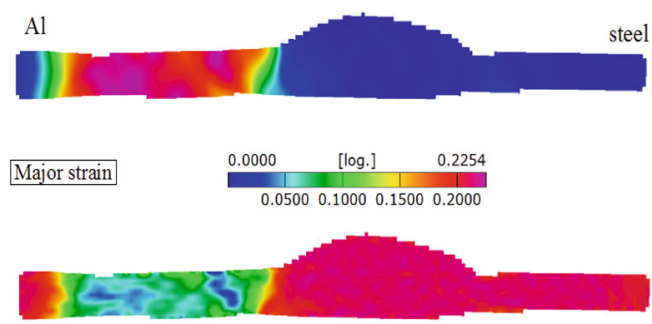

\begin{tabular}{llll|l|}
\hline Minor strain & -0.1949 & [log.] & 0.0111 \\
\hline & -0.1500 & -0.1000 & -0.0500
\end{tabular}

(c) Axial strain $=10 \%$.
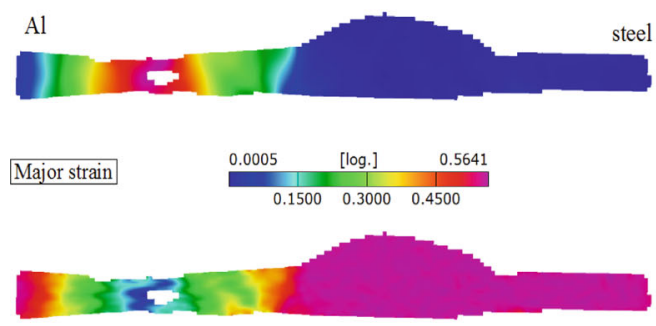

Minor strain

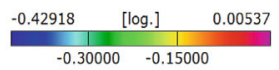

(e) Axial strain $=17 \%$.
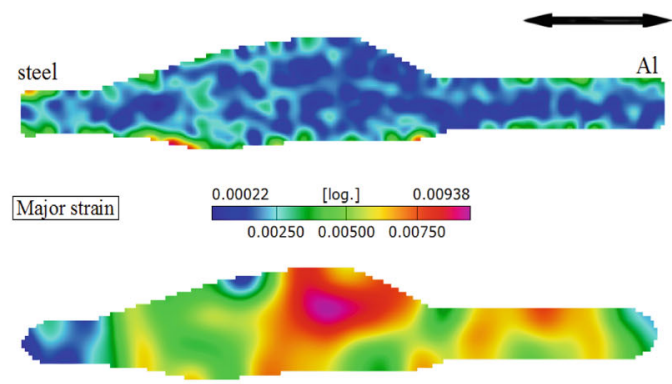

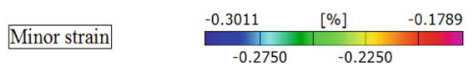

(b) Axial strain $=0.01 \%$.

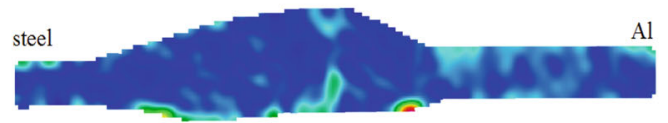

\begin{tabular}{llll}
\hline Major strain & -0.00026 & [log.] & 0.02307 \\
\cline { 3 - 4 } & 0.00750 & 0.01500
\end{tabular}

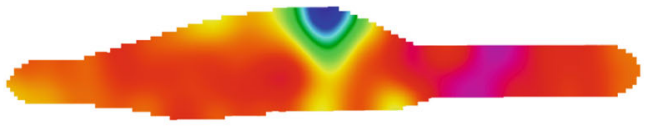

\begin{tabular}{ll|ll}
\hline Minor strain & -0.6270 & {$[\%]$} & -0.1243 \\
\hline & -0.4500 & -0.3000
\end{tabular}

(d) Axial strain $=0.1 \%$.
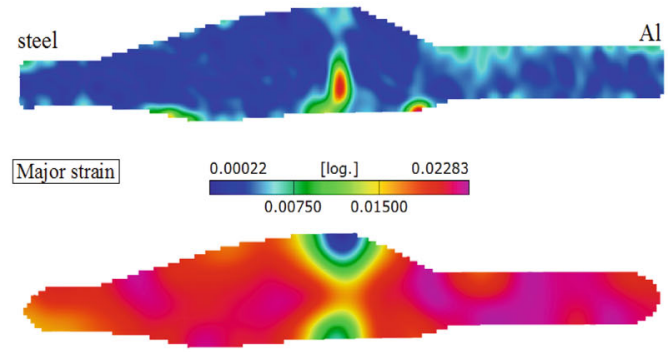

\begin{tabular}{cccc}
\hline Minor strain & -0.7030 & {$[\%]$} & -0.1633 \\
\hline & -0.6000 & -0.4500 & -0.3000
\end{tabular}

(f) Axial strain $=0.17 \%$

Fig. 13 Sequence of major and minor strain development at different axial strains of through-thickness surface of AA2024/DP780 1.27 mm/1 mm brazed specimens for laser/MIG (left) and CMT (right) brazing methods

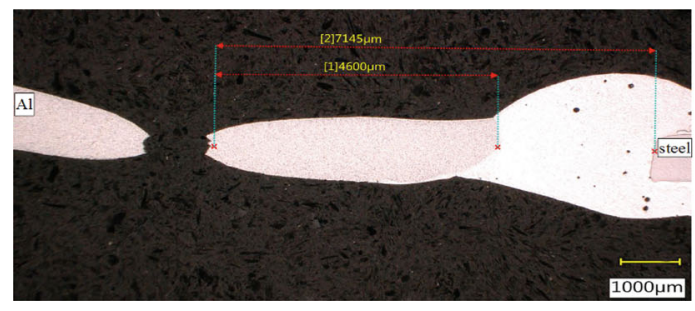

(a) Laser/MIG brazing.

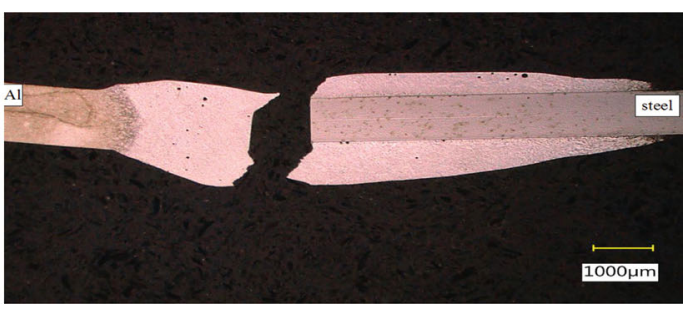

(b) CMT brazing.

Fig. 14 OM images of (LT) plane of fractured AA2024/DP780 $1.27 \mathrm{~mm} / 1 \mathrm{~mm}$ brazed specimens for a laser/MIG and b CMT brazing methods 


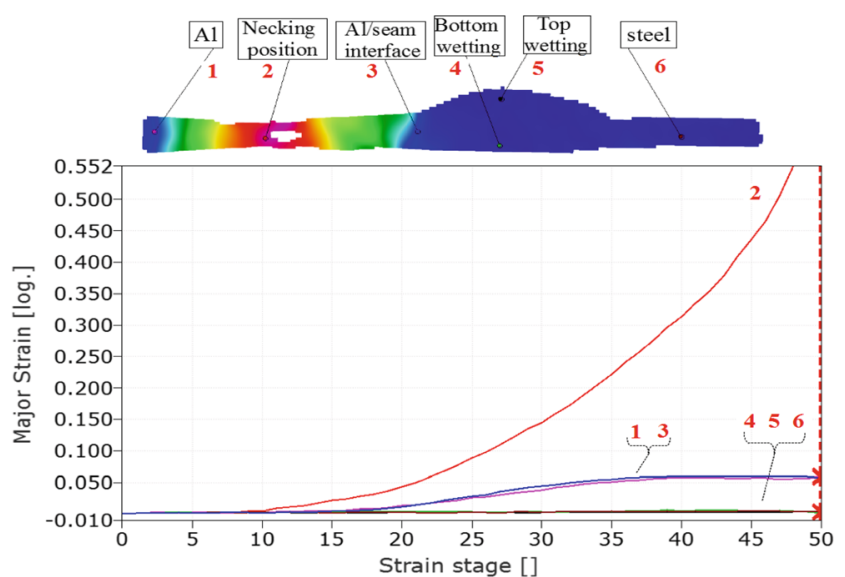

(a) Laser/MIG brazing specimens.

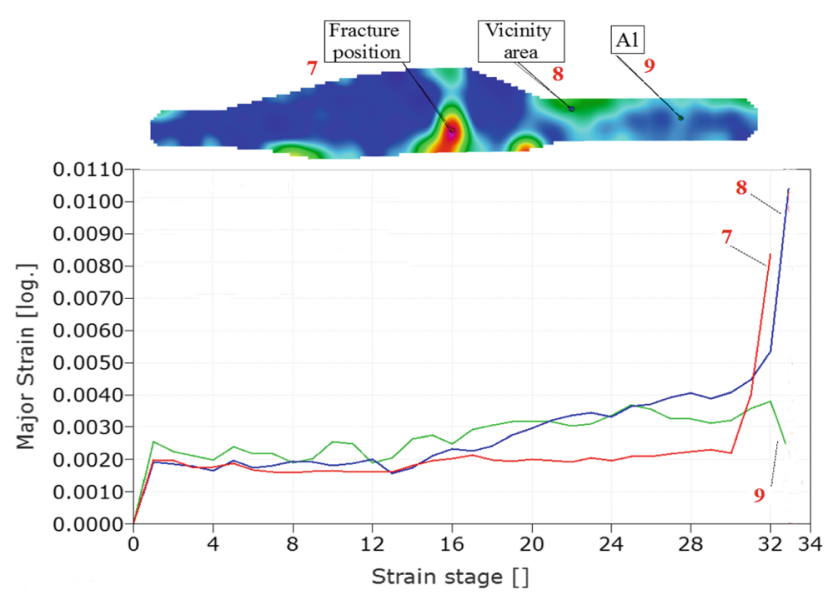

(b) CMT brazing specimens.

Fig. 15 Point strain histories at different positions of AA2024/DP780 $1.27 \mathrm{~mm} / 1 \mathrm{~mm}$ brazed specimens for $\mathbf{a}$ laser/MIG and $\mathbf{b}$ CMT brazing methods

input during wetting process [13], which was different for both laser/MIG and CMT methods as discussed earlier. The average thicknesses of IMCs and the average wetting lengths of brazed specimens from laser/MIG and CMT brazing methods are presented in Table 2 .

\subsection{Microhardness measurements}

Figures 7 and 8 present the microhardness profiles of AA2024/DP780 $1.27 \mathrm{~mm} / 1 \mathrm{~mm}$ brazed joints made by laser/MIG and CMT brazing methods respectively. The DP steel side showed considerably higher hardness values in the region adjacent to the steel/aluminum interface for both methods. Hardness profile then decreased gradually until it merged with that of base metal of DP steel. For the aluminum side, the weld seam adjacent to the steel/aluminum interface showed lower hardness values compared with that of aluminum base metal as it transformed to cast structure during solidification after brazing [12]. A significant drop of hardness values was observed in the region adjacent to weld seam in aluminum base metal for hybrid brazing specimens (Fig. 7). This may be attributed to the effect of heat input during hybrid brazing process which may have caused partial annealing in this region and resulted in hardness drop [18]. Consequently, stress concentration mostly occurs in this region during subsequent forming process as presented later in this paper. In contrast, CMT specimens did not show any hardness drop in aluminum base metal. The hardness values increased gradually from weld seam boundary until it merged with that of aluminum base metal (Fig. 8).

\subsection{Uniaxial tensile test results}

Figure 9 shows major strain maps superimposed on the actual deformed specimens for laser/MIG hybrid and CMT brazing methods. Visible necking can be observed in area adjacent to the brazed area in aluminum base metal for hybrid brazed specimens. However, a catastrophic fracture occurred in the brazed area at steel/aluminum interface for CMT brazed specimens. The major and minor strain maps and strain distribution profiles that were obtained along the tested samples for hybrid and CMT brazing methods are shown in Fig. 10a and b respectively. For hybrid brazing specimens, a much larger major strain of about 0.35 occurred on the aluminum side with visible necking. The steel side exhibited a rather small major strain of only 0.015 and the brazed area remained undeformed. In contrast, for CMT brazed specimens, both aluminum and steel sides remained undeformed with only a small deformation of about 0.017 in the brazed region prior to its catastrophic fracture.

Figure 11 shows a comparison of the localized true stress-true strain curves to fracture of the brazed specimens for hybrid and CMT brazing. It is clear that hybrid specimens resulted in a much larger localized elongation of $28 \%$ and lower static tensile stress of $142 \mathrm{MPa}$. In contrast, CMT specimens resulted in negligible localized elongation of $0.76 \%$ and a higher static tensile stress of $184 \mathrm{MPa}$. The difference in the mechanical behavior of the brazed specimens from both methods may be attributed to the difference in fracture location as well as the effect of the heat input during the respective brazing processes. For hybrid specimens, visible necking occurred in aluminum BM adjacent to brazing area due to strength degradation after brazing process and the strain localized in this area (Fig. 10a). The specimens became more ductile and more localized elongation was obtained. In contrast, CMT brazing specimens failed in the thick brazing area which required more load to be fractured. In addition, much lower strain development was observed in brazing area of CMT specimens compared with that occurred in aluminum BM of 
Fig. 16 Geometries of notched specimens of AA2024/DP780 $1.27 \mathrm{~mm} / 1 \mathrm{~mm}$ brazed specimens made by laser/MIG brazing method with: a 0.6 width ratio, b 0.4 width ratio, and $\mathbf{c} 0.2$ width ratio

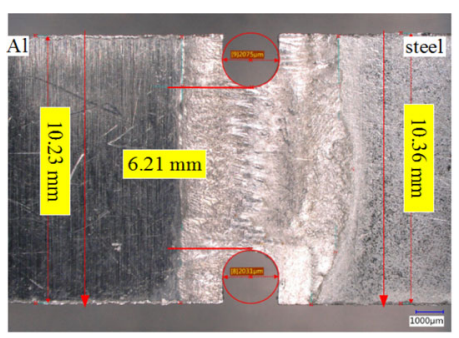

(a) 0.6 width ratio.

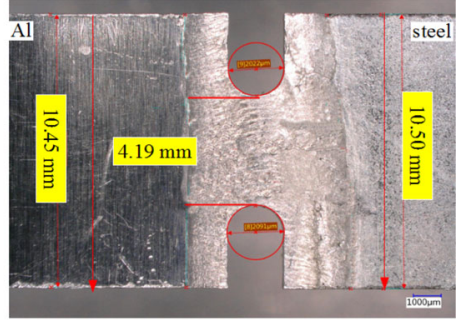

(b) 0.4 width ratio.

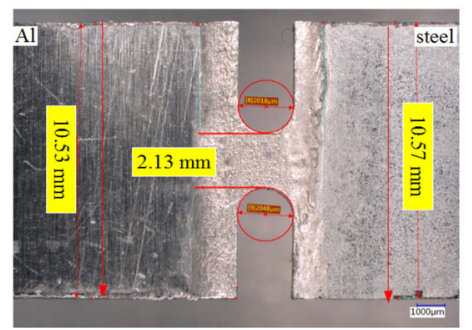

(c) 0.2 width ratio.

laser/MIG specimens (Fig. 10b). It is to be noted that hybrid brazing was used to decrease the amount of heat input by increasing the brazing speed, and consequently lower the thickness of IMCs layer at faying surfaces in the brazing area to get better mechanical performance. However, the area adjacent to the brazing area in the aluminum side was affected by this heat and became softer than the aluminum $\mathrm{BM}$ and the brazed area. In other words, loss of strength due to the partial annealing occurred adjacent to braze during hybrid brazing process. This phenomenon is well known in fusion welding and brazing processes of aluminum metal sheets $[8,18]$. The loss of strength was also observed from the hardness values measured along the brazed specimens where a drop in hardness profile, compared with that of aluminum BM and brazing area, occurred in the area adjacent to the brazing area (see Fig. 7). In contrast, CMT brazing specimens did not show this behavior, i.e., no loss of strength occurred in the aluminum sheet. Thus, the strain concentrated in the thick brazing area which possessed lower hardness values and fractured at higher static tensile stress than that of hybrid brazing specimens which failed at the weaker area of aluminum BM (see Fig. 8). The degree of annealing in aluminum BM sheet during hybrid brazing process, and consequently the degradation of the strength, depends largely on the heat input and the exposure time.

Due to such large difference in deformation and fracture behavior for the two methods, further investigations with small-scale tensile specimens were conducted. Magnified
Fig. 17 Major and minor strain distributions in miniature notched specimens of AA2024/DP780 $1.27 \mathrm{~mm} / 1 \mathrm{~mm}$ for laser/MIG brazing (0.6 width ratio)

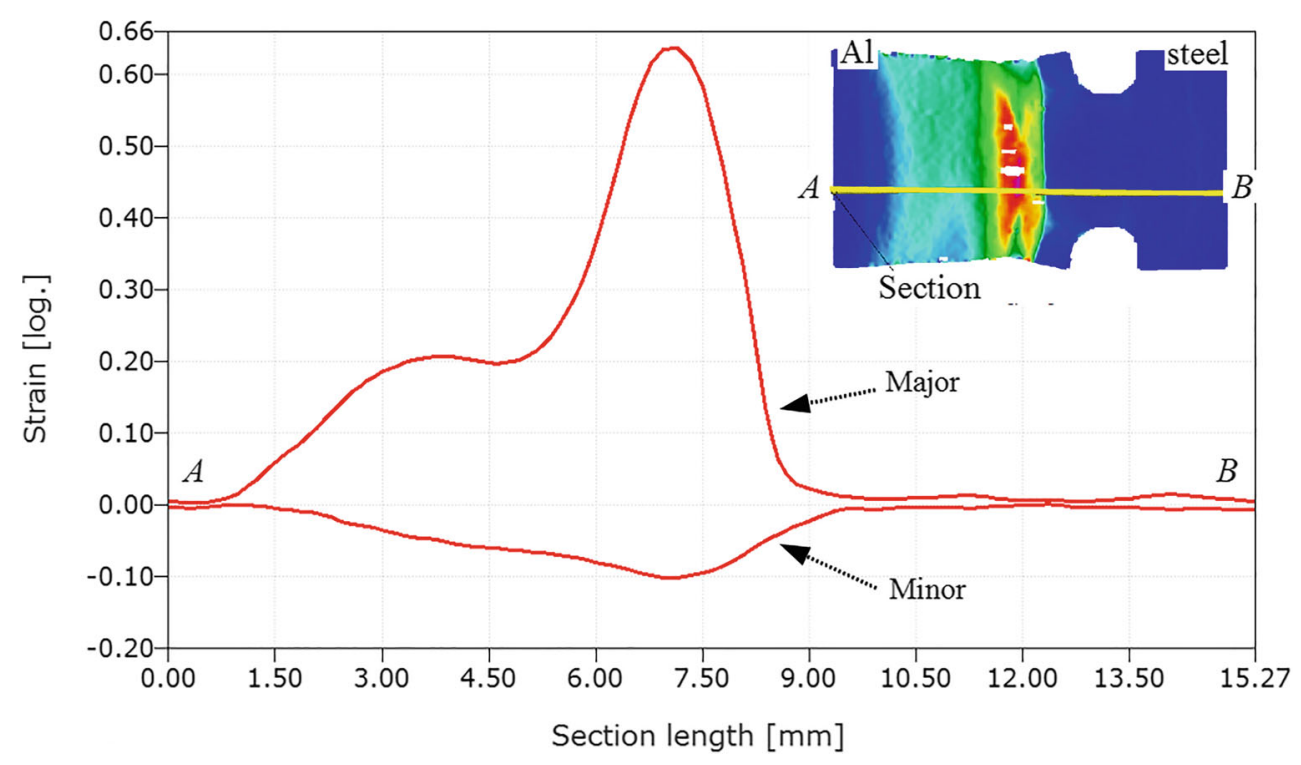



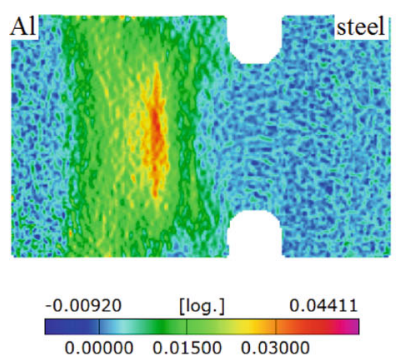

(a) Axial strain $=0.75 \%$.
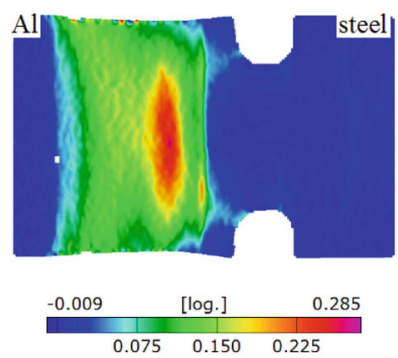

(c) Axial strain $=6.5 \%$.

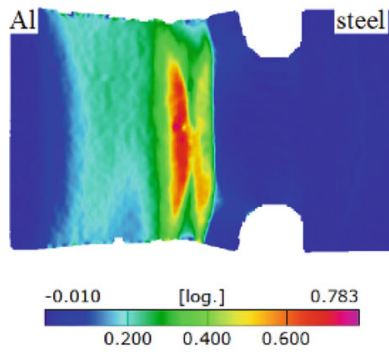

(e) Axial strain $=12.5 \%$.
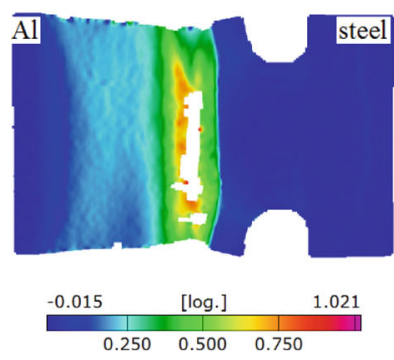

(g) Axial strain $=14 \%$
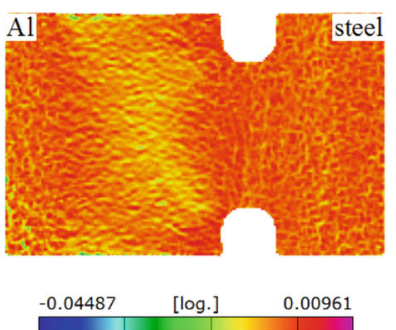

$\begin{array}{lll}-0.03000 & -0.01500 & 0.00000\end{array}$

(b) Axial strain $=0.75 \%$.
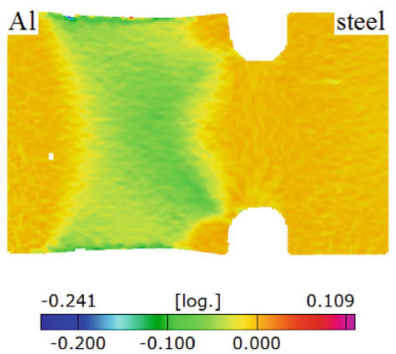

(d) Axial strain $=6.5 \%$.

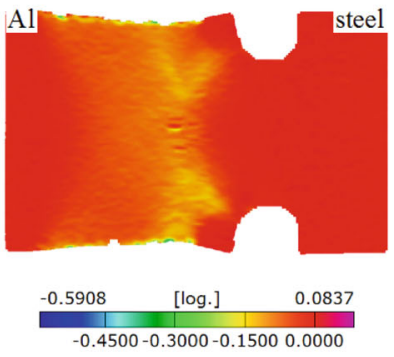

(f) Axial strain $=12.5 \%$.
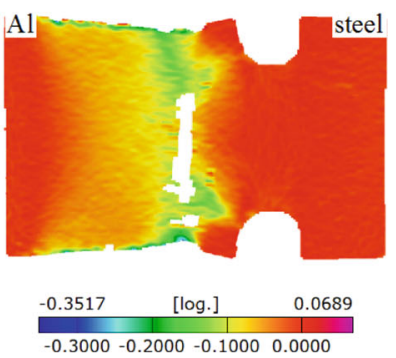

(h) Axial strain $=14 \%$.

Fig. 18 Major (left column) and minor (right column) strain development at different axial strains in miniature notched specimens of AA2024/DP780 $1.27 \mathrm{~mm} / 1 \mathrm{~mm}$ for laser/MIG brazing (width ratio $=0.6$ )

images (20X) of the brazed area and its vicinity were taken from width region (ND) and through-thickness (LT) surfaces using miniature in situ uniaxial tensile test jig in conjunction with the optical microscope.

Figure 12 presents photograph of deformed test samples as well as major and minor strain maps from width region (ND plane) just before fracture for laser/MIG and CMT brazing specimens. For hybrid brazing specimens, necking in the width region was clearly visible in aluminum BM adjacent to the brazed area without any deformation in the brazed area (Fig. 12a and c). In contrast, results of CMT brazing specimens showed no necking or deformation in the width region in vicinity of the brazed area (see Fig. 12b). However, the brazed area incorporated different deformation behavior according to the distribution of the major strain in this area as shown in Fig. 12b and d. For example, weld seam, wetting area, and the interface area show different colors in the major strain spectrum corresponding to large, moderate, and low strains, respectively. The interface area of CMT brazing specimens has the lowest value of major strain (see Fig. 12d). Fracture occurred catastrophically in this area.

Figure 13 demonstrates the development of major and minor strain in the through-thickness region (LT) for laser/MIG and CMT brazing specimens. For hybrid brazing specimens, the strain maps show that strain increased in the area adjacent to the brazed area where necking in the thickness direction was clearly visible in aluminum $\mathrm{BM}$ and a ductile fracture occurred in this area with no deformation in the brazed area (see Fig. 13a, c, and e). However, a negligible increase in strain for CMT brazing specimens was observed (see Fig. 13b, d, and f). The strain concentrated in a region at the side faying surface, i.e., at the steel/aluminum interface, as seen in Fig. 13f leading to a catastrophic brittle fracture. This may be attributed to lack of adhesion between aluminum and steel at side faying surface (steel/aluminum interface) due to the lack of zinc coating layer at steel edge. It was reported that the zinc coating layer on steel sheet surfaces is crucial in improving the wetting and adhesion between molten aluminum and steel substrate at the faying surfaces [10, 25]. However, the edge of steel sheets to be joined was cut and milled. So, the zinc coating layer at the side faying surface was removed and consequently affected the adhesion at steel/aluminum interface. The difference between the failure of brazed specimens for laser/MIG and CMT brazing methods can be clearly seen in the through-thickness optical images from polished sections as presented in Fig. 14.

Figure 15 shows plots of point strain histories at six (16) and three (7-9), different positions in brazed specimens for laser/MIG and CMT brazing test specimens respectively. It is to be noted that the strain at fracture point 2 started to increase earlier than any other point in brazed specimen until fracture for hybrid brazing specimens. This means that strain localization set in early in aluminum BM in the area 
Fig. 19 Major and minor strain distributions in miniature notched specimens of AA2024/DP780 $1.27 \mathrm{~mm} / 1 \mathrm{~mm}$ for laser/MIG hybrid brazing (width ratio $=0.4$ )

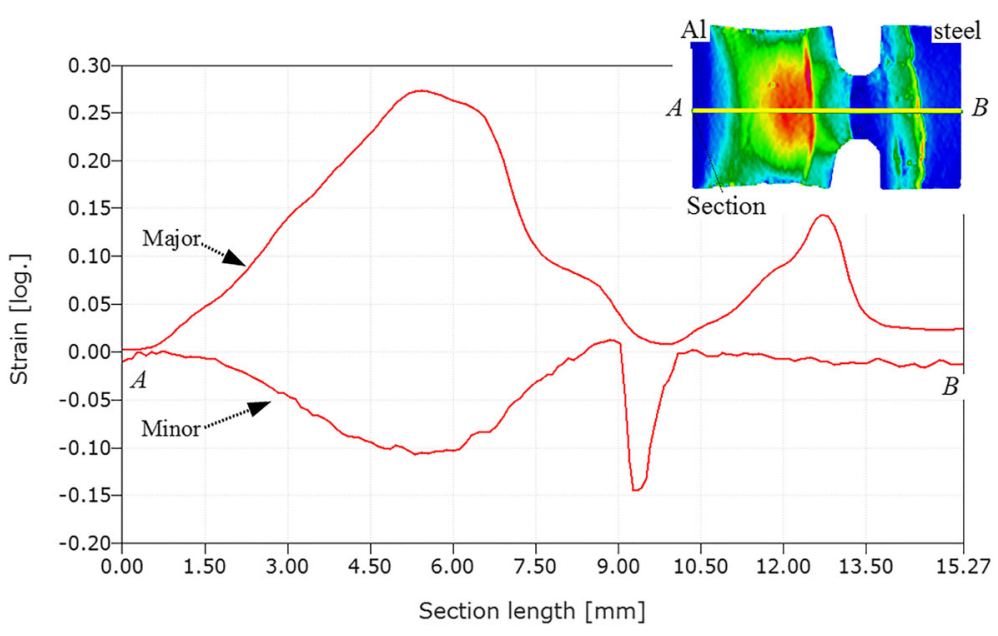

adjacent to the brazed region. In contrast, the strain in CMT brazing specimen was slightly higher in the area in vicinity of the brazed region, point 8 , in aluminum BM until close

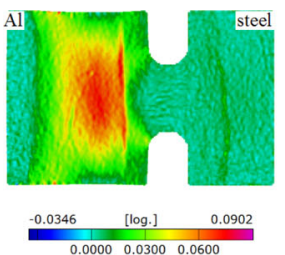

(a) Axial strain $=2 \%$.

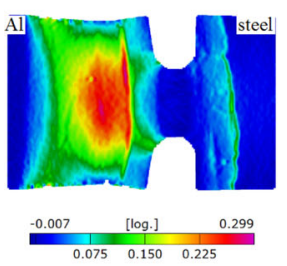

(c) Axial strain $=8 \%$.

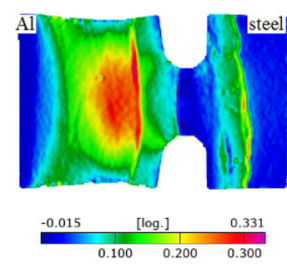

(e) Axial strain $=9.5 \%$.

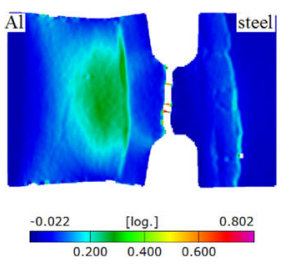

(g) Axial strain $=10.5 \%$.

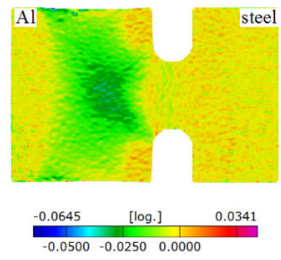

(b) Axial strain $=2 \%$.

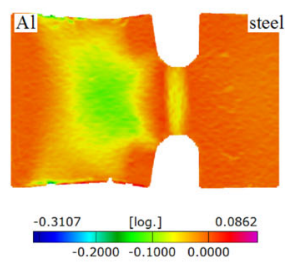

(d) Axial strain $=8 \%$.

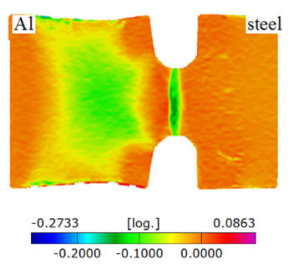

(f) Axial strain $=9.5 \%$.

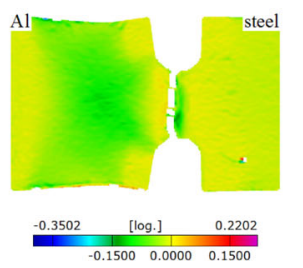

(h) Axial strain $=10.5 \%$.
Fig. 20 Major (left column) and minor (right column) strain development in miniature notched specimens of AA2024/DP780 1.27 $\mathrm{mm} / 1 \mathrm{~mm}$ for laser/MIG brazing (width ratio=0.4) to fracture when a catastrophic increase in strain occurred at the fracture point 7 . This means that the area in vicinity of the brazed area was only slightly affected by the heat input during the CMT brazing process and the softening of this region was not dominant.

Since failure of laser/MIG brazed specimens always occurred in aluminum BM, the brazed area (points 4 and 5 in Fig. 15a) remained less strained. Therefore, to "enable" failure in the brazed area, specimens of hybrid brazing were notched in the width direction at the steel/aluminum interface with different width ratios. The presence of a notch was expected to cause failure of the brazed region rather than the weak adjacent area in aluminum BM.

Brazed specimens from laser/MIG hybrid brazing with initial width of $10 \mathrm{~mm}$ and average wetting length of 4.5 $\mathrm{mm}$ were cut at steel/aluminum interface to reduced width of $6 \mathrm{~mm}, 4 \mathrm{~mm}$, and $2 \mathrm{~mm}$, respectively, as shown in Fig. 16 . Width ratio was defined as the ratio of reduced width over the full width of the specimen. Three samples per each width ratio were subjected to uniaxial tension along $\mathrm{X}$-axis (i.e., perpendicular to the notch direction), while magnified images of deformed specimens were continuously recorded using an optical microscope. A speckle pattern was applied to the notch region and Aramis system was used for obtaining strain maps in the notched region.

Figure 17 shows a plot of major and minor strain distributions along the length $A B$ of the notched specimen for a width ratio of 0.6. The failure still occurred in the area adjacent to the brazing area in aluminum BM. As noted earlier, the degradation of the strength in this area was due to the partial annealing that occurred from the heat input during laser/MIG brazing process. The strain tended to concentrate in this area rather than in the brazed area. No strain development occurred in the brazed or wetting length areas (see Fig. 18). Similar results were obtained at the next lower width ratio of 0.4 as shown in Fig. 19. The strain was still localized in the affected area adjacent to the brazing 
Fig. 21 Major and minor strain distributions in miniature notched specimens of AA2024/DP780 $1.27 \mathrm{~mm} / 1 \mathrm{~mm}$ for laser/MIG hybrid brazing (0.2 width ratio)

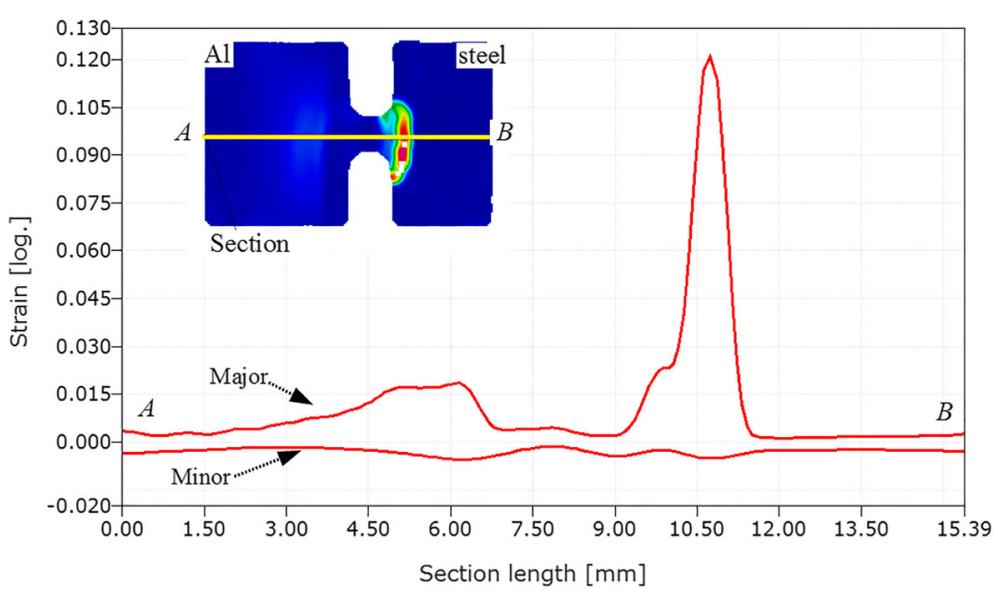

area and extended to the weld seam zone in the transition area between weld seam and aluminum BM. Moreover, the

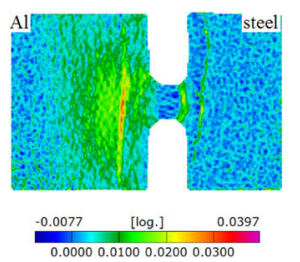

(a) Axial strain $=0.45 \%$.

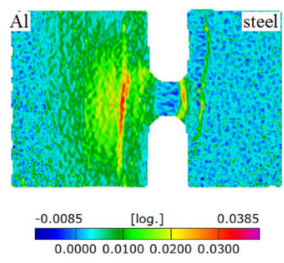

(c) Axial strain $=0.55 \%$.

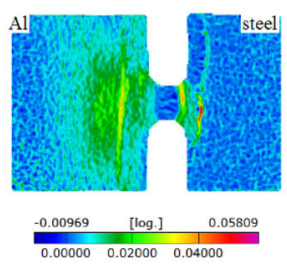

(e) Axial strain $=0.65 \%$.

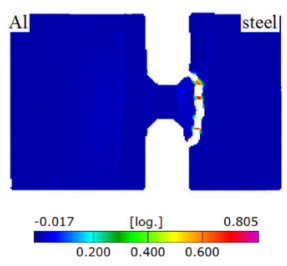

(g) Axial strain $=2 \%$.

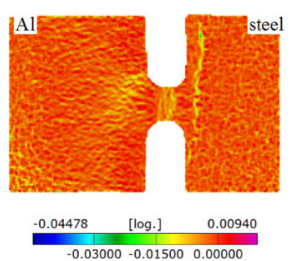

(b) Axial strain $=0.45 \%$.

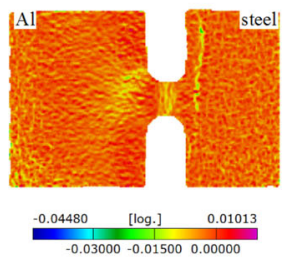

(d) Axial strain $=0.55 \%$.

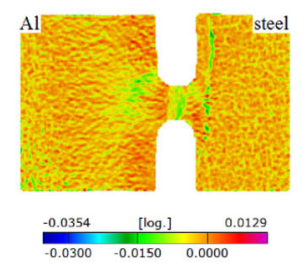

(f) Axial strain $=0.65 \%$.

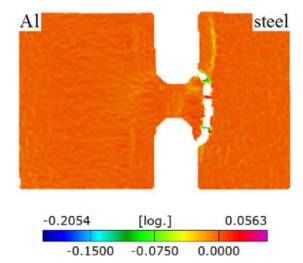

(h) Axial strain $=2 \%$.
Fig. 22 Major (left column) and minor (right column) strain development at different axial strains in miniature notched specimen of AA2024/DP780 $1.27 \mathrm{~mm} / 1 \mathrm{~mm}$ for laser/MIG hybrid brazing (width ratio $=0.2$ ) strain concentration occurred in the transition area between the brazed area and steel BM due to the increase in load transfer through the upper and lower wetting areas (shear area) with decreasing the cross-section at the brazed zone. The minor strain distribution in Fig. 19 shows that necking occurred in width direction in the affected area adjacent to the brazed area as well as in the brazed area itself. However, it was closer in the brazed area and the fracture occurred catastrophically at steel/aluminum interface. This may be caused by lack of adhesion between aluminum and steel at steel/aluminum interface (side faying surface) because of absence of the zinc coating during edge preparation of steel sheets before joining process. In addition, the presence of different materials in this area consisting of steel, aluminum weld seam, and IMC layer and their different physical and mechanical behavior could further localize the fracture process. When the strain concentrates in this area, the deformation starts first in the weaker or more ductile material (aluminum weld seam) within the brazed area. Due to the diversity of relative deformation between materials in this area, separation occurred in the weaker/stronger material interface and consequently crack and subsequent fracture took place and propagated from this point. The development of major and minor strain from the start of loading until the fracture at the steel/aluminum interface, for a width ratio of 0.4, is shown in Fig. 20.

On further decreasing the width ratio to 0.2 , the strain initiated in the area adjacent to the brazed area. However, it was higher and localized in the transition area between the brazed area and steel BM and consequently separation and fracture occurred in this area as shown in Fig. 21. This also can be seen from the development of the major and minor strains presented in Fig. 21. This may be attributed to the increase in the load transfer to the smaller wetting area (i.e., shear area) that could not bear this load. Excessive loading of this shear area could separate the upper and lower wetting lengths from the steel substrate (see Fig. 22g and h). 


\section{Conclusions}

Brazing of steel to aluminum has been a challenge in the past. The two brazing methods studied in the present work, laser/MIG hybrid and CMT brazing methods, could join the DP780 steel to AA2024 sheets successfully. However, brazed specimens produced from each method showed significantly different deformation behavior:

1. Uniform appearance of brazed specimens from CMT brazing method was obtained with longer wetting lengths and better transition between brazing area and steel substrate at the end of wetting lengths.

2. Both brazing methods yielded IMC layer thickness less than $10 \mu \mathrm{m}$. The IMC layer thickness was lower for CMT brazing specimens than that of laser/MIG brazing specimens.

3. Loss of strength was observed for laser/MIG brazed specimens. The hardness values measured along through-thickness plane showed a significant drop of hardness profile in the area adjacent to the brazing area in aluminum BM. This was attributed to partial annealing occurred in this area due to the heat input from continuous fusing during brazing process. Failure always occurred in this area.

4. No drop in hardness profile was observed in aluminum $\mathrm{BM}$ for CMT brazed specimens. Aluminum base material was not affected by the heat input and a catastrophic failure occurred in the brazing area at steel/aluminum interface. This was due to the lack of zinc coating layer in the side faying surface which was removed during edge preparation before brazing process.

5. Results of laser/MIG brazed notched tensile specimens showed that the degradation of tensile properties of aluminum BM was dominant for all aspect ratios. On decreasing the width aspect ratio, the location of final fracture depended on the relative strengths (loading capacity) of different regions of brazed joints.

6. Results of steel-to-aluminum brazed joints proved that better wetting length and lower IMC layer thickness are not the only factors that improve the mechanical behavior of brazed joints. The susceptibility of the aluminum BM and time of exposure to the heat sources during joining process are also important.

\section{Compliance with ethical standards}

Conflict of interest The authors declare that they have no conflict of interest.
Open Access This article is licensed under a Creative Commons Attribution 4.0 International License, which permits use, sharing, adaptation, distribution and reproduction in any medium or format, as long as you give appropriate credit to the original author(s) and the source, provide a link to the Creative Commons licence, and indicate if changes were made. The images or other third party material in this article are included in the article's Creative Commons licence, unless indicated otherwise in a credit line to the material. If material is not included in the article's Creative Commons licence and your intended use is not permitted by statutory regulation or exceeds the permitted use, you will need to obtain permission directly from the copyright holder. To view a copy of this licence, visit http:// creativecommonshorg/licenses/by/4.0/.

\section{Appendix}

The procedures of construction of the localized true stresstrue strain curves are as follows:

The load $(F)$ and displacement are recorded by tensile machine controller. Major strain $\left(\epsilon_{1}\right)$ and minor strain $\left(\epsilon_{2}\right)$ developments are measured at the point of necking/fracture (localized strains) using Aramis. Strain development in thickness direction $\left(\epsilon_{3}\right)$ is measured by:

$\epsilon_{3}=-\left(\epsilon_{1}+\epsilon_{2}\right)$

The current width $w$ and current thickness $t$ are calculated by:

$$
\begin{gathered}
w=w_{0} e^{\epsilon_{2}} \\
t=t_{0} e^{\epsilon_{3}}
\end{gathered}
$$

Where $w_{0}$ and $t_{0}$ are the initial width and thickness of aluminum BM of the TBB specimen.

The current area $(A)$ at the point of necking/fracture:

$A=w t$

The true stress $(\sigma)$ is calculated by:

$\sigma=\frac{F}{A}$

The true stress $(\sigma)$ vs. true major strain $\left(\epsilon_{1}\right)$ are plotted to construct localized true stess-true strain curves for both laser/MIG and CMT specimens as shown in Fig. 11.

\section{References}

1. Agudo L, Weber S, Pinto H, Arenholz E, Wagner J, Hackl H, Bruckner J, Pyzalla A (2008) Study of microstructure and residual stresses in dissimilar al/steels welds produced by cold metal transfer. In: Materials science forum, vol 571. Trans Tech Publications, pp 347-353

2. ASTM E8/E8M-13a (2013) Standard test methods for tension testing of metallic materials. Annual Book of ASTM standards. ASTM 
3. Ducker Worldwide. 2015 North American Light Vehicle Aluminum Content Study. Tech. rep., DriveAluminum (2014). Accessed: April 2016

4. Fronius (2015) CMT: cold metal transfer. http://www. digitalweldingsolutions.com/cmt.pdf. Retrieved: April 2016

5. Habibnia M, Shakeri M, Nourouzi S, Givi MB (2015) Microstructural and mechanical properties of friction stir welded $5050 \mathrm{Al}$ alloy and 304 stainless steel plates. Int $\mathbf{J}$ Adv Manuf Technol 76(5-8):819-829

6. Haddadi F, Abu-Farha F (2015) Microstructural and mechanical performance of aluminium to steel high power ultrasonic spot welding. J Mater Process Technol 225:262-274

7. Katayama S (2004) Laser welding of aluminium alloys and dissimilar metals. Weld Int 18(8):618-625

8. Kou S (2003) Welding metallurgy. Wiley, New York

9. Kreimeyer M, Sepold G (2002) Laser steel joined aluminiumhybrid structures. In: Proceedings of ICALEO, vol 2

10. Lin S, Song J, Yang C, Fan C, Zhang D (2010) Brazability of dissimilar metals tungsten inert gas butt welding-brazing between aluminum alloy and stainless steel with $\mathrm{Al}-\mathrm{Cu}$ filler metal. Mater Des 31(5):2637-2642

11. Mathieu A, Pontevicci S, Viala JC, Cicala E, Matteï S, Grevey D (2006) Laser brazing of a steel/aluminium assembly with hot filler wire (88\% Al, 12\% Si). Mater Sci Eng: A 435:19-28

12. Merklein M, Johannes M, Lechner M, Kuppert A (2014) A review on tailored blanks-production, applications and evaluation. J Mater Process Technol 214(2):151-164

13. Moller F, Thomy C (2013) Laser welding and brazing of dissimilar materials. In: Katayama $S$ (ed) Handbook of laser welding technologies. Woodhead Publishing, pp 255279

14. Ozaki H, Kutsuna M (2009) Laser-roll welding of a dissimilar metal joint of low carbon steel to aluminium alloy using $2 \mathrm{kw}$ fibre laser. Weld Int 23(5):345-352

15. Ozaki H, Kutsuna M, Nakagawa S, Miyamoto K (2010) Laser roll welding of dissimilar metal joint of zinc coated steel to aluminum alloy. J Laser Appl 22(1):1-6
16. Padmanabhan R, Oliveira MC, Menezes LF (2008) Deep drawing of aluminium-steel tailor-welded blanks. Mater Des 29(1):154-160

17. Padmanabhan R, Oliveira MC, Menezes LF (2011) Lightweight metal alloy tailor welded blanks. In: Kinsey BL, Wu X (eds) Tailor welded blanks for advanced manufacturing. Woodhead Publishing, pp 97-117

18. Schwartz MM (2003) Brazing. ASM International

19. Shah LH, Ishak M (2014) Review of research progress on aluminum-steel dissimilar welding. Mater Manuf Process 29(8):928-933

20. Shi H, Qiao S, Qiu R, Zhang X, Yu H (2012) Effect of welding time on the joining phenomena of diffusion welded joint between aluminum alloy and stainless steel. Mater Manuf Process 27(12):1366-1369

21. Sun Z, Ion JC (1995) Review laser welding of dissimilar metal combinations. J Mater Sci 30:4205-4214

22. Thomy C, Vollertsen F (2012) Laser-MIG hybrid welding of aluminium to steel-effect of process parameters on joint properties. Weld World 56(5-6):124-132

23. Tricarico L, Spina R (2010) Experimental investigation of laser beam welding of explosion-welded steel/aluminum structural transition joints. Mater Des 31(4):1981-1992

24. Yang J, Li Y, Zhang H, Guo W, Weckman D, Zhou N (2015) Dissimilar laser welding/brazing of 5754 aluminum alloy to DP 980 steel: mechanical properties and interfacial microstructure. Metall Mater Trans A 46(11):5149-5157

25. Zhang H, Liu J (2011) Microstructure characteristics and mechanical property of aluminum alloy/stainless steel lap joints fabricated by MIG welding-brazing process. Mater Sci Eng: A 528(19):6179-6185

26. Zhang W, Sun D, Han L, Liu D (2014) Interfacial microstructure and mechanical property of resistance spot welded joint of high strength steel and aluminium alloy with 4047 AlSi12 interlayer. Mater Des 57:186-194

Publisher's note Springer Nature remains neutral with regard to jurisdictional claims in published maps and institutional affiliations. 